whilst having a risk ration in excess of 7 in comparison to the rate following local anaesthesia is not calculated. It would also have been of use to include the actual re-admission rates for each procedure classification. In our own multi-centre study (2), ureteroscopy yielded a re-admission rate of over $13 \%$ which may be loosely compared to the $18 \%$ complication rate following ureteroscopy in this series despite an unknown rate of re-admission.

There is no doubt that there is a huge drive, both from a patient acceptability view and from a health economic stand, for day case surgery to continually evolve. As it does so, there is a vital need for perpetual audit and analysis of results to ensure that patient interests are not overlooked or indeed sacrificed in the name of such progress.

\section{References}

1. RCS Commission on the provision of surgical services. Guidelines for day surgery. A report of the working party of the Royal College of Surgeons of England, March 1992.

2. Sinclair AM, Gunendren T, Pearce I: Day case urological surgery : Are we improving? BJU Int. 2007; 99: 491-3.

Dr. Ian Pearce

Consultant Urological Surgeon Manchester Royal Infirmary Manchester, United Kingdom E-mail:pearcey@totalise.co.uk

\title{
Re: The Role of Squamous Differentiation in Patients with Transitional Cell Carcinoma of the Bladder Treated with Radical Cystectomy
}

\author{
Alberto A. Antunes, Luciano J. Nesrallah, Marcos F. Dall'Oglio, Carlos E. Maluf, Cesar Camara, \\ Katia R. Leite, Miguel Srougi \\ Division of Urology, University of Sao Paulo Medical School, Sao Paulo, Brazil and Hospital Sirio \\ Libanes, Sao Paulo, Brazil
}

Int Braz J Urol, 33: 339-346, 2007

To the Editor:

Antunes et al., provide an interesting insight into the adverse prognostic role of squamous differentiation of transitional cell carcinoma (TCC) of the bladder. In their retrospective study, both disease recurrence and mortality were statistically higher in those patients with squamous differentiation, with the adverse prognosis being confirmed on a multivariate analysis. Some deficiencies were noted in the study, most importantly the small number of patients, and the lack of information about the presence and extent 
of lymph node metastases, which may have affected results. Certainly these results have not been demonstrated by other investigators that have found no statistically significant difference between squamous differentiation and pure TCC, although many have shown mortality reductions with other subtypes such as adenocarinoma, carcinosarcoma and small cell carcinoma of the bladder (1-3). Nonetheless, it remains crucial that further, preferably randomized or well conducted retrospective studies are performed, to confirm which TCC subtypes truly portend a poorer prognosis. This data could then be used to assist in the integration of chemotherapy or radiotherapy, together with surgery in the management of these aggressive cancers in order to improve clinical outcomes.

\section{References}

1. Richie JP, Waisman J, Skinner DG, Dretler SP: Squamous carcinoma of the bladder: treatment by radical cystectomy. J Urol. 1976; 115: 670-2.

2. Ghoneim MA, el-Mekresh MM, el-Baz MA, el-Attar IA, Ashamallah A: Radical cystectomy for carcinoma of the bladder ; critical evaluation of results in 1026 cases J Urol. 1997; 158: 393-9.

3. Rogers CG, Palapattu GS, Shariat SF, Karakiewic PI, Bastian PJ, Lotan Y, et al.: Clinical outcomes following radical cystectomy for primary non transitional cell carcinoma of the bladder compared to transitional cell carcinoma of the bladder J Urol. 2006; 175: 2048-53.

Dr. Mark Frydenberg

Department of Urology

Monash Medical Centre, Monash University

Victoria, Australia

E-mail: frydenberg@optusnet.com.au

\title{
Re: The Role of Squamous Differentiation in Patients with Transitional Cell Carcinoma of the Bladder Treated with Radical Cystectomy
}

\author{
Alberto A. Antunes, Luciano J. Nesrallah, Marcos F. Dall'Oglio, Carlos E. Maluf, Cesar Camara, \\ Katia R. Leite, Miguel Srougi \\ Division of Urology, University of Sao Paulo Medical School, Sao Paulo, Brazil and Hospital Sirio \\ Libanes, Sao Paulo, Brazil
}

Int Braz J Urol, 33: 339-346, 2007

To the Editor:

Squamous differentiation is well known to occur in the bladder urothelial carcinoma and represents the most common form of mixed differentiation (1-5). When defined by the presence of intercel- lular bridges and/or keratinization in urothelial carcinoma, it occurs in $21 \%$ of urothelial carcinomas of the bladder, and in $44 \%$ of tumors of the renal pelvis (2-3). Its frequency increases with grade and stage 